\title{
An Experimental Analysis on performance of Content Management Tools in an Organization
}

\author{
Dr. Sandip Kadam \\ University of Management Studies, Nagpur India \\ sandipkadam1983@gmail.com
}

\begin{tabular}{|c|c|}
\hline Article History & Abstract \\
\hline $\begin{array}{l}\text { Article Submission } \\
1 \text { November } 2013 \\
\text { Revised Submission } \\
19 \text { March } 2014 \\
\text { Article Accepted } \\
25 \text { May } 2014 \\
\text { Article Published } \\
30 \text { June } 2014\end{array}$ & $\begin{array}{l}\text { In any organization for organizing information, one must fully understand the value } \\
\text { of a content management system, which helps in providing solutions by managing } \\
\text { the data based on the knowledge of the enterprise. There is a big confusion related } \\
\text { to the functions performed by the content management system, some products are } \\
\text { also there which does not show full performance. These products are web content } \\
\text { management system, managing records and documents, and some enterprise } \\
\text { managing content. This research paper help in finding the mismatching between the } \\
\text { customer needs and the product information. The article includes the differences in } \\
\text { the functions of the content management system and other systems which are used } \\
\text { for companies.to manage documents, techniques are needed and require a lot of } \\
\text { information to store, manage, and retrieve. Many software is available to keep the } \\
\text { record of the data to store the information and manage the data. One of them is the } \\
\text { Enterprise Content Management tool which helps in finding solutions regarding the } \\
\text { context. The products of content management are dissected, linked, examined by } \\
\text { using a table to figure out the functions of the market products. This paper shows } \\
\text { the confusion in the framework on the demand side, and at the same time feedback } \\
\text { on confusion in the supply side by decreasing the satisfaction of the company in } \\
\text { respect of knowledge and information management. } \\
\text { Keywords: Content Management Systems CMS, CMS Tools }\end{array}$ \\
\hline
\end{tabular}

\section{Introduction}

In this fast-growing environment, the important assets are the information present at the staff clearing. Management of the information is needed for setting up and the management of the documents becomes the key aspect. In this digital world, digital documents are required and need to be handled with proper care to perform the task in the organization, if there is lack of management then the results cannot be achieved timely.

$\mathrm{ECM}$ (Enterprise content management) is a type of mechanism technique for providing enough solutions to support and instruct the task. The variables do not allow one to find out which is best suitable for the factual environment. There are several terms which are associated with the content management those are:

\section{- Data}

Information stored in small pieces, without any human interactions, these are the collection of database store in the organization. It is one of the unit which needs to be handled.

\section{- Information}

It is a kind of data in various forms, like, sound, music, text, images, pictures, animations, documents, etc. it can have human interactions or may not have direct human interactions, anything can be considered as the information which makes data interpreted and unreal relations.

- Content:

The information when used for several different purposes the information gets converted to the content. It is the value of the sum of all primary information like significance, separateness. This is a sum of information and the layer of content. 
- Knowledge: It is known as the storage house of the humans, where information is stored, not just for communication. It is something one knows about with full confidence because of their practical experience.

Data is considered the single word present as the parts of a speech. The information is stored for specific content. Knowledge is all about the mental state of the person who can understand because of experience. The person who speaks about the information knows about the concept for better communication, which is further converted to sounds, images and record it for future use. The data, information, knowledge are different from each other and there are many challenges for managing the content for any organization or firm. Computer machines are used for preparing data, not the content. Earlier times, people use the computer machine for loading, processing, and finding the output of data, but in recent times, it is used for searching and output of the content. The information present in the computer needs to be separated so that its originality is not reduced and information must be separated into various elements so that it is treated as the information, not data. So it required to manage the content to use information as in the context.

Content management is the document piece of information that needs to implement as the management of knowledge as the project. It is the method or the technique for collecting and managing and publishing the content in the company or firm. It is something not about the creation of writing. The fact is the conjugation of content management and information technology services. Information technology is connected with the process to collect information and further use for publishing. It gives them control over the creation and dividing of information. They allow the knowledge and the controlling of value and to decide the receive for managing the transmitted data.

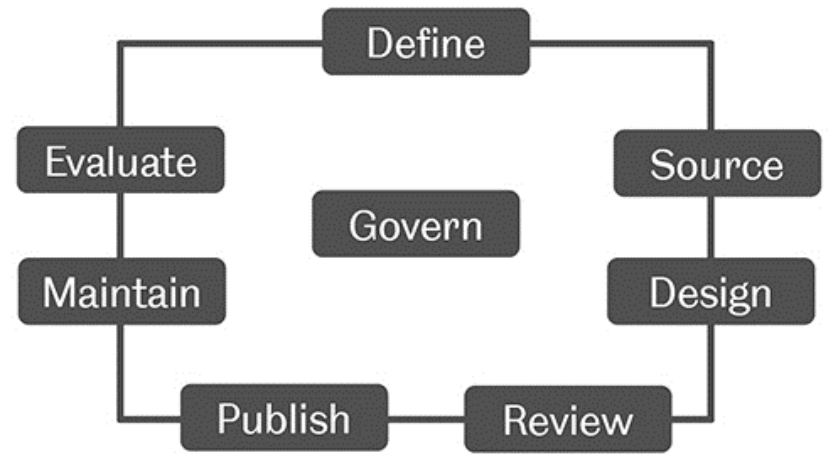

Fig 1 : Content management system overview

\section{II.The Lifecycle of Content Management}

The lifecycle of the content management system has three steps that are collection, management, and publication. The information which is managed is published and transformed directly.

\section{The collection system}

This system has the instruments, procedures, and human resources which will be used for obtaining the content, and for the second part, elaboration is done with single parts, and finally, it is available for publication. The process required is:

- Writing of the content

- Acquiring the information

- Converting, the content into different layers and convert into a markup language.

- Summing up, to separate content and assign a tag, so that, content is inserted

- Collection of services, programs, and functionality that provide support to the collection system. 


\section{The management system}

In the cycle of content management, this phase help to organize the content and it accountable for storage and instrument used for the metadata. This system helps in identifying the administration, workflow practices, repository that authorize one to know which content is own by which organization. It helps in finding the answers to the questions put about the content, collection, and the publication.

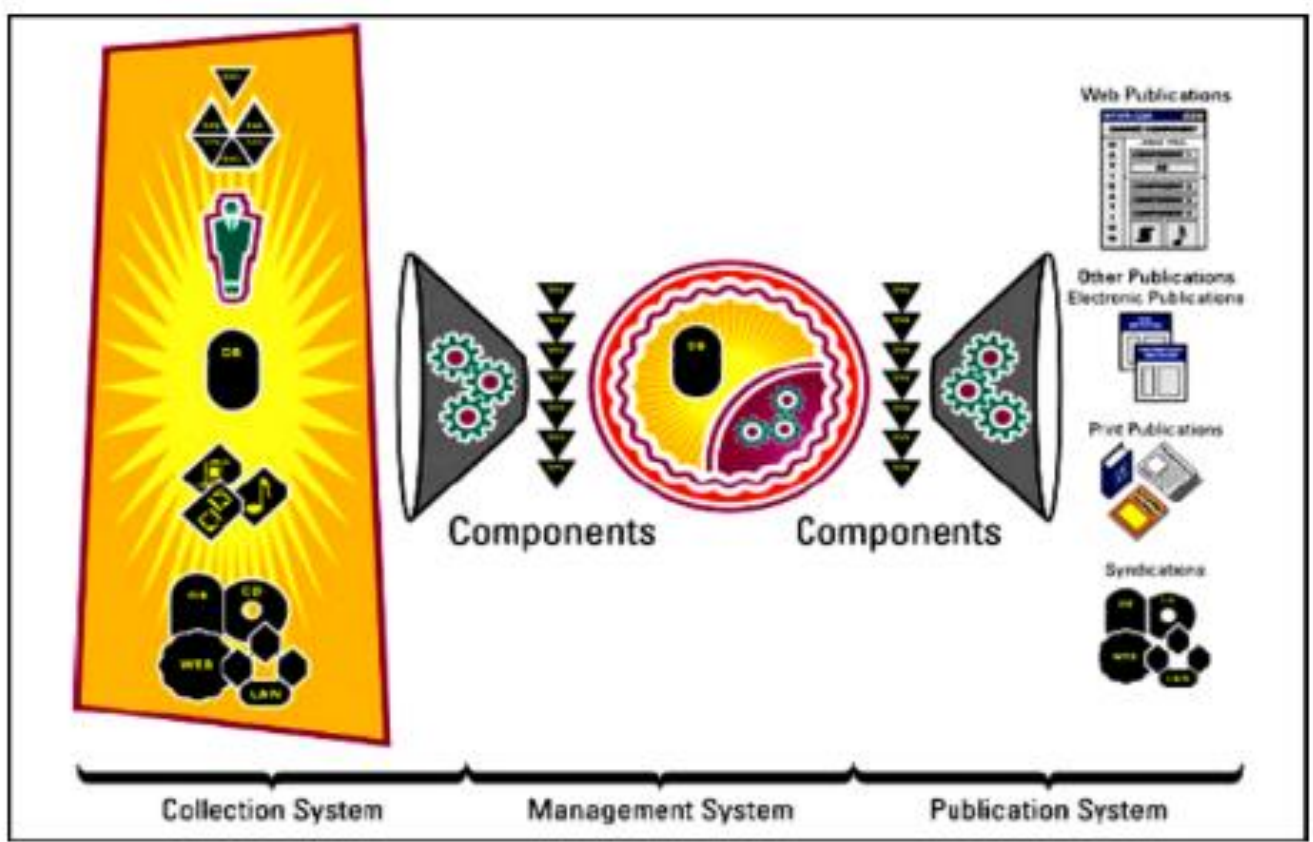

Fig 2 : Content management system lifecycle

\section{The publication system}

This system is the final last stage for the content, as it helps in searching out the content from the repository and immediately creates from the final publication, it is not only used for external people but also used in internal communications. The output generated is not only the website but can be in CD-Rom, print, articles, newspaper clipping, etc. A publishing system is defined as the part of the information which is released that is identified and show characteristics publisher, people to watch, messages, responsibility. The important is the templates known as the programs, used for creating a link with the content management system with the final out of the publication released. The pages of information are automatically created for a single content.

\section{III.Products of Content Management}

The content management prodcuts aim to find the difference between the actual products and the content management system that are given, which is different from this but have many different characteristics. There are times when it is different from the original products and sometimes specialize in one particular area and think that they are supporting the lifecycle fully. It is divided into four categories for defined it properly.

\section{a) Content Management System}

The complete information about the content management system is shown in figure 3 given below which is shown to be true in the passage given above for describing the system of content management. 


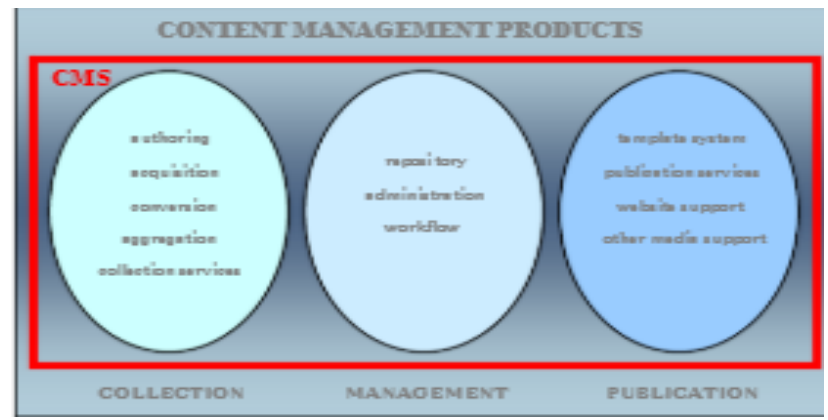

Fig 3 : Content management system products

\section{b) Web Content Management system}

When an organization wants to update or create the website, then a high volume of information is required for updation so a web content management system is used for the same. It helps in creation of a lot many content and also allows managing the content like text-sound, images, videos by using some simple devices. It is the product of the content management system because all applications came from it for managing the content( managing the content of an organization which is required to be published on web.)

\section{c) Document and record management system}

DM systems are the type of system used for carrying out the records and management of high volumes of documents in the original format so that storage becomes easy. It is created, stored by the repository and workflow based on rules and metadata. Record management works in both digital and paperwork by having access to secure methods of the database.

\section{d) Organization content management system}

It is a kind of system for keeping records of the information of all documents, websites, data, etc. It does not depend on any format to manage its information and can be processed based on knowledge. The organizational content management is the collection of all the management system that is web, document, record management system all the assumptions and correlation is shown in table 1 and figure 4 . If they are not internal functionalities then it is marked with $\mathrm{X}$, or we can say they are not developed.

Table 1: Relation between CMS, WCMS, RM,DM

\begin{tabular}{|c|c|c|c|c|c|c|}
\hline \multicolumn{2}{|c|}{ MAJ OR FUNCTIONALITIES } & \multirow{2}{*}{$\frac{C M}{x}$} & \multirow{2}{*}{$\frac{\text { wCM }}{\mathrm{x}}$} & \multirow{2}{*}{$\begin{array}{c}\text { DM } \\
\mathrm{x}\end{array}$} & \multirow[t]{2}{*}{ RM } & \multirow{2}{*}{$\begin{array}{c}\text { ECM } \\
\mathrm{X}\end{array}$} \\
\hline \multirow{5}{*}{$\begin{array}{l}\overline{\bar{g}} \\
\frac{\mathrm{g}}{\overline{3}} \\
\end{array}$} & Authoring & & & & & \\
\hline & Acquisition & $\mathrm{x}$ & $\mathrm{x}$ & $\mathrm{x}$ & $\mathrm{x}$ & $\mathrm{x}$ \\
\hline & Conversion & $x$ & & $\mathrm{x}$ & $x$ & $x$ \\
\hline & Aggregation & $\mathrm{x}$ & & $\mathrm{x}$ & & $x$ \\
\hline & Collection Services & $\mathrm{x}$ & & $\mathrm{x}$ & & $\mathrm{x}$ \\
\hline \multirow{3}{*}{$\begin{array}{l}\text { ज्ञ } \\
\text { है } \\
\text { है } \\
\text { है }\end{array}$} & Repository & $\mathrm{x}$ & & $\mathrm{x}$ & $\mathrm{x}$ & $\mathrm{x}$ \\
\hline & Administration & $x$ & $\mathrm{x}$ & $\mathrm{x}$ & $x$ & $x$ \\
\hline & Workflow & $\mathrm{x}$ & $\mathrm{x}$ & $\mathrm{x}$ & $x$ & $\mathrm{x}$ \\
\hline \multirow{4}{*}{ 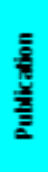 } & Template System & $x$ & $x$ & & & $x$ \\
\hline & Publication Services & $\mathrm{x}$ & $x$ & $(x)$ & $(x)$ & $(x)$ \\
\hline & Website support & $x$ & $x$ & & & $x$ \\
\hline & Other media support & $\mathrm{x}$ & & & & \\
\hline
\end{tabular}




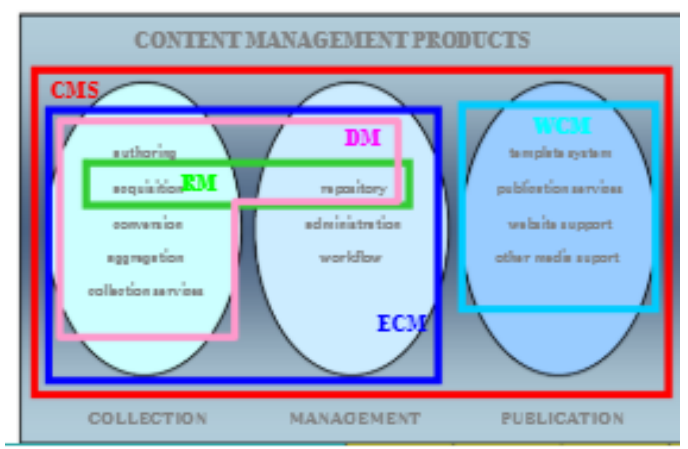

Fig 4: WM ,RM, ECM products

\section{Evaluation and survey}

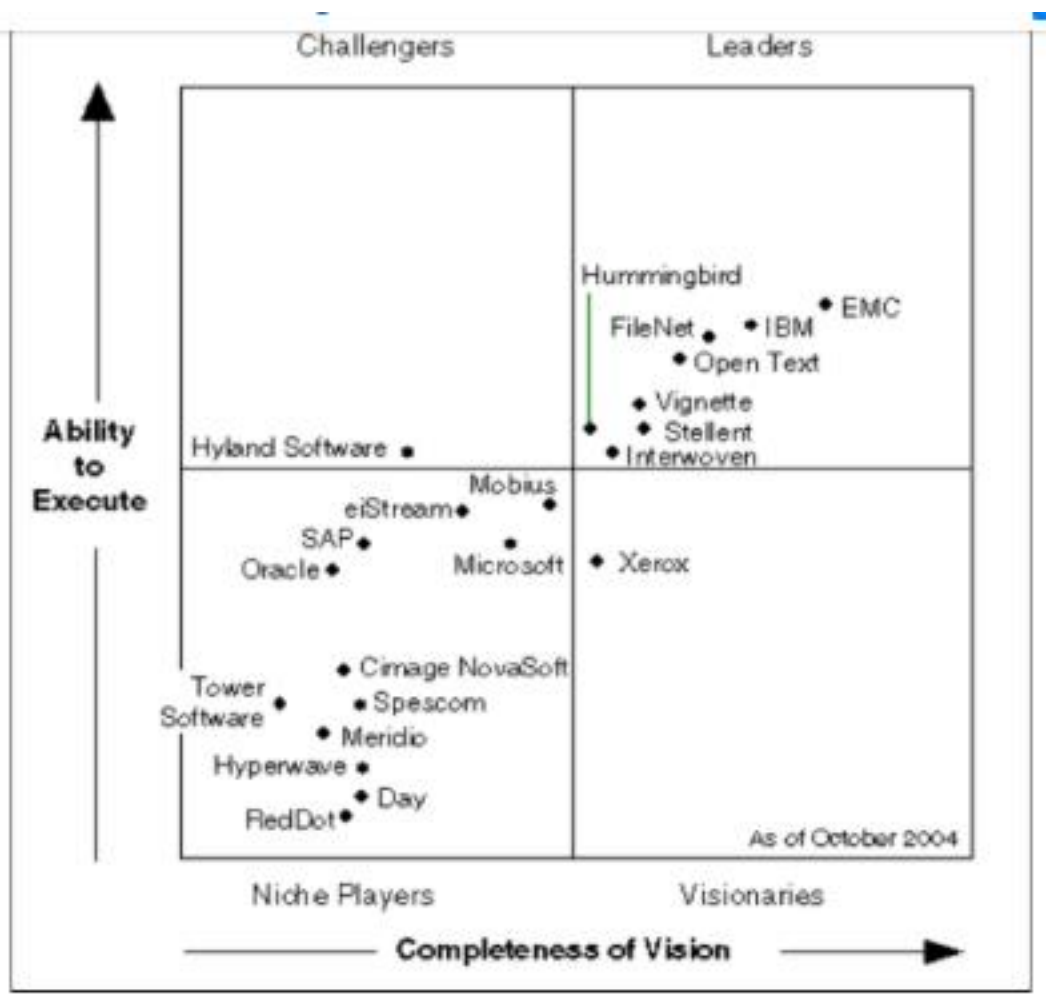

Fig 5: WM ,RM, ECM products Graph quadrants

The analysis, evaluation, and comparison are done on the selected products, which is shown in figure 5. The functions of the content management lifecycle is followed. The collection system considered the process of authority for supporting, acquisition process support, converting formats, summing process, reusing of information, and divide of metadata. The management system shows: Security system, format for a content store is neutral, index of information done automatically, research is done at a fast pace, using of technology and other languages, modified content, single interface working, managing all types of formats, update, delete, comparison with other applications, workflow in automatical manner, flexible, security process. The publication: use of a template for publishing, content conversion, create more publications, personal system, multi-language system 


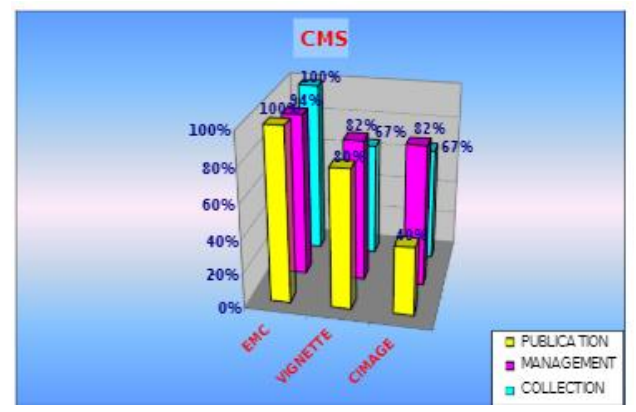

Fig 6: CMS products

\section{Conclusion}

In the study, it is found that content management products attain great success with market characteristics. There are three main areas where the content management system is evolved those are collection, management, publication. They are in these areas because of the potential of marker and barrier do not enter weaker sections. The companies are attracted because of the low costs. The evaluation must be done on products and select the best to create a relation between the client and the organization. Nowadays the websites are the main source of content management and supporting the companies from creation, storage, and publishing formats.

\section{References}

[1] AIIM (2013) The Global Community of Information Professionals. http://www.aiim.org/

[2] Alalwan, J.A. and Weistroffer, H.R. (2012) Enterprise Content Management Research: A Comprehensive Review. Journal of Enterprise Information Management, 25, 441-461. http://dx.doi.org/10.1108/17410391211265133

[3] THOTProject.http://www.aopandalucia.es/inetfiles/agencia_innovacion_estructura/14122012112320.p df Scott, J.E. (2011)

[4] User Perceptions of an Enterprise Content Management System. Proceedings of the 44th Hawaii International Conference on Systems Science (HICSS-44 2011), Koloa, 4-7 January 2011, 1, 9, 4-7.

[5] Haug, A. (2012) The Implementation of Enterprise Content Management Systems in SMEs. Journal of Enterprise In-formation Management, 25, 349-372. http://dx.doi.org/10.1108/17410391211245838

[6] Van Rooij, J.C. (2013) Legacy Issues in the Implementation of Enterprise Content Management (ECM). International Journal of Information, 3, 120-123.

[7] ISO 2709:2008, Information and Documentation—Format for Information Exchange. http://www.iso.org/iso/iso_catalogue/catalogue_tc/catalogue_detail.htm?csnumber=41319

[8] ISO 15836:2009, Information and Documentation-The Dublin Core Metadata Element Set. http://www.iso.org/iso/catalogue_detail.htm?csnumber=52142

[9] ISO 15489-1:2001, Information and Documentation—Records Management—Part 1: General. http://www.iso.org/iso/catalogue_detail?csnumber=31908

[10] ISO 23950:1998, Information and Documentation-Information Retrieval (Z39.50)-Application Service Definition and Protocol Specification. http://www.iso.org/iso/catalogue_detail.htm?csnumber=27446

[11] ISO 10244:2010, Document Management-Business Process Baselining and Analysis.http://www.iso.org/iso/home/store/catalogue_tc/catalogue_detail.htm?csnumber=45935

[12] Zhang, H. and Babar, M.A. (2013) Systematic Reviews in Software Engineering: An Empirical Investigation. Information and Software Technology, 55, 1341-1354.

[13] Kitchenham, B. (2004) Procedures for Performing Systematic Reviews. Keele University, Keele, 33.

[14] Brereton, P., Kitchenham, B.A., Budgen, D., Turner, M. and Khalil, M. (2007) Lessons from Applying the Systematic Literature Review Process within the Software Engineering Domain. Journal of Systems and Software, 80, 571-583. http://dx.doi.org/10.1016/j.jss.2006.07.009 
[15] Kitchenham, B. and Brereton, P. (2007) Introduction to Special Section on Evaluation and Assessment in Software Engineering EASE06. Journal of Systems and Software, 80, 1423-1424. http://dx.doi.org/10.1016/j.jss.2006.10.031

[16] Staples, M. and Niazi, M. (2007) Experience Using Systematic Review Guidelines. Journal of Systems and Software, 80, 1425-1437. http://dx.doi.org/10.1016/j.jss.2006.09.046

[17] Kitchenham, B. and Charters, S. (2007) Guidelines for Performing Systematic Literature Reviews in Software Engineering, Technical Report EBSE 2007-001,Keele University and Durham University Joint Report. 